\title{
The coronavirus: Black swan and endowment shock
}

\author{
Guillermo Peña Blasco*1 \\ Universidad de Zaragoza, Departamento de Análisis Económico, Gran Vía 2, 50005 Zaragoza, Spain
}

Received: 17 November 2020 / Accepted: 12 May 2021

\begin{abstract}
An external shock caused by an extraordinary and unpredictable effect, a "black swan" like COVID-19, is analyzed. It implies a shift of endowment in financial markets, and its effects on economic inequality, financial deepening and total economic income. Theoretical models are proposed, where the public sector seeks alternatives to a lockdown, allowing self-regulation of the economy, taxing capital or seeking joint policies with other states. In the first model, the economy is self-regulating with the help of the financial sector. Nonetheless, inequality is generated and in other models, the public sector tries to intervene. First, the public sector minimizes inequality by taxing capital, allowing a redistribution of wealth and income, with a tax rate that depends only on the differential impacts of the black swan on the different markets. Finally, a coordination of policies between the different countries affected is proposed to prevent black swans and other negative externalities. This is feasible depending on the tax rate, household benefits and administration costs.
\end{abstract}

\section{Keywords}

Wealth inequality / Financial sector / Economic crisis / COVID-19 / Black swan.

\section{O coronavirus: cisne negro e perturbación na dotación de capital}

\section{Resumo}

Analízase un shock externo provocado por un efecto extraordinario e imprevisible, un "cisne negro", como a COVID-19. Tal shock leva a un cambio de dotación de capital nos mercados financeiros, e ten efectos sobre a desigualdade económica, o desenvolvemento financeiro e a renda económica. Propóñense modelos teóricos nos que o sector público busca alternativas ao confinamento, permitindo a autorregulación da economía, gravando o capital ou buscando políticas conxuntas con outros Estados. No primeiro modelo, a economía autorregúlase coa axuda do sector financeiro. Porén, xérase desigualdade económica, polo que nos seguintes modelos o sector público intenta intervir. En primeiro lugar, o sector público minimiza a desigualdade gravando o capital, o que permite unha redistribución da riqueza e da renda, cun tipo impositivo que só depende dos impactos diferenciais do cisne negro nos distintos mercados. Por último, proponse unha coordinación de políticas entre os distintos países afectados para evitar os cisnes negros e outras externalidades negativas. Isto é factible en función do tipo impositivo, das preferencias dos fogares e dos custos de administración.

\section{Palabras clave}

Desigualdade de riqueza / Sector financeiro / Crise económica / COVID-19 / Cisne negro.

JEL Codes: D31, G21, 012.

\section{Introduction}

Bad news can become better or even good news if government and other institutions intervene correctly. So, an initially negative shock can finally impact positively depending on the public policies. In fact, some authors have questioned the policies for the novel coronavirus (Gros, 2020) that have led to the "great lockdown". This has also led to a global economic crisis that may be even greater than the

\footnotetext{
* Corresponding author: gpena@unizar.es

1 I would like to express my gratitude for the comments and suggestions of the anonymous referees and the editors of the Journal, they have improved the paper.
} 
Great Recession, which suggests that we have to learn from previous mistakes. Other alternative policies are possible. Currently, there are over one million deaths caused by the pandemic. The main objective of this paper is to provide alternative public policies for the lockdown in order to control the sanitary crisis, but also the economic crash.

The effects of pandemics on the economy are rarely studied (Amankwah-Amoah, Khan \& Wood, 2020), and understanding their distributional effects is crucial (Adams-Prassl, Boneva, Golin \& Rauh, 2020). The interest in studying the major determinants of economic crises and the roots of business failures has increased in recent decades, especially since the beginning of the Great Recession and this interest continues with the COVID-19 pandemic. Nonetheless, there is still a lack of systematic understanding (Amankwah-Amoah et al., 2020), for instance there is very little knowledge about the impact of wealth inequality on economic crises.

This paper aims to explain the effects on assets and the implications on income and wealth inequality, financial deepening and economic growth of an initial random endowment shock caused by an event that has no relevant precedent in recent history with exceptional and unpredictable impact on financial markets (called "black swan", such as the coronavirus shock). An additional objective for this paper is to provide further alternatives, even complementary, to the lockdown established in many countries for solving the economic and sanitary crisis of the COVID-19.

The main objective of the government in this paper, in addition to fighting the coronavirus, is to reduce, or at least maintain, income distribution as it was prior to the crisis. The proposed alternatives to the lockdown cover, at least, three fields: the first one studies the impact of the black swan on relevant economic variables by assuming that the lockdown has not been established but a selfregulation by financial markets and industry is allowed without intervention by the public sector. The second one is the application of taxes to combat the inequality generated in the first case, and the last field considers the provision of subventions, unemployment benefits and public goods in order to reduce inequality and to promote the end of the sanitary crisis.

In the first case, an increase in wealth inequality year-by-year is observed in the short term, and the Gross Domestic Product (GDP) increases on $t=1$ but decreases on $t=2$, while the financial sector increases both periods. Finally, the initial equilibrium is again achieved in the long term with a selfregulated economy thanks to the financial sector.

However, economic inequality is reached, thus another model is developed in which the public sector intervenes to reduce this inequality, using a different tax rate of income and wealth for each individual as a control instrument to fulfill the target policy. Two models are developed, the first one for achieving the objective through the revenue tools of the public sector: taxes, levying more highly the consumers most benefited or, at least, least affected by the black swan. The other way is using public expenditure in a coordinated way with the public administrations of other countries. The target is to reduce income inequality by direct subventions or to promote the public provision of drugs or vaccines in order to directly avoid the sanitary crisis, true origin of the black swan.

As the models considered in this paper avoid the presence of a lockdown, then the first actual initial sharp fall of the economy due to the compulsory reduction of demand and supply is not taken into account, and so it does not appear. In contrast, the models are compatible with a postlockdown scenario in which some drugs to fight the COVID-19 are being developed and there is a production of vaccines, which increases GDP in $t=1$. This leads to an asymmetric growth of the economy that increases income inequality, with the financial sector initially reallocating resources between savers and lenders ${ }^{2}$. Nonetheless, this leads to a financial crisis in $t=2$ due to the withdrawal of deposits and cancellation of loans when the initial endowment shock is finished. There is a new fall from $t=2$ to $t=3$ until the crisis is over in $t=3$, turning back to the initial scenario without the black swan, with the expected rate of economic growth equal to 0 (equilibrium with steady state).

\footnotetext{
2 In a context of extremely low interest rates, maybe a slight increase of the reference rates of monetary policy would help to improve economic activity thanks to the potential existence of a reversal rate (Brunnermeier \& Koby, 2018).
} 
So, this paper implicitly assumes for the current crisis a a $W$ shape, where the first down-peak due to the economic crisis is a consequence of the lockdown (not reflected in these models). There is an expansion of the financial sector due to the black swan and household's savings and there is an additional fall, due to the withdrawal of the deposits (as the next models reflect, a V recovery due to the absence of lockdown).

The main reason for the increase on GDP after the endowment shock is the increase of savings for many households. It is influenced by the existence of "precautionary saving" as a reaction to uncertainty ${ }^{3}$, a possible solution for the so-called "empirical consumption puzzles". The reason for this increase of savings under uncertainty is that individuals aim to be prudent and to protect from risk for the possible worse times in the future. This reaction has been empirically tested for wealth by authors such as Carroll \& Samwick (1998), for consumption by Menegatti (2010) and for savings by Chamon, Liu \& Prasad (2013). Nonetheless, some other studies fail to find such relationship (Benito, 2006).

As Amankwah-Amoah et al. (2020) state, studies in the past have usually overlooked the economic effects of black swan events on businesses. The effects of the financial markets on economic growth were initially proposed by Schumpeter (1912), positively affecting the economy. Nonetheless, negative random shocks can also affect the economy, negatively in this case. The reason for this is the presence of a black swan, a concept suggested by Taleb (2007) and which refers to unusual events with an extraordinary and unpredictable effect. The coronavirus pandemic has been accepted as a black swan in the financial markets (Küçükçayli \& Akinci, 2020). In fact, this black swan, due to questionable public policies, could lead to undesirable consequences on credit and consumer behavior among other and, due to this "snowball effect", turning the black swan into the snowball (Davola, 2020).

Pandemics and wars or conflicts, believed the most significant crises, have often had a direct impact on income inequality, with detrimental effects on the economy in both the short and medium term, as Sayed \& Peng (2020) point out. These authors also suggest that pandemics can have narrowing effects on the income gap. However, there are growing effects on income inequality and perverse income redistribution (Adams-Prassl et al., 2020, Furceri, Loungani, Ostry \& Pizzuto 2020; Galletta \& Giommoni, 2020).

Several authors recognize an empirical relationship between credit and economic inequality related to financial crises (Perugini, Hölscher \& Collie 2015), as a first step in economic crises. These authors only study, consecutively, the impact of credit growth on financial crises, and then, the impact of income inequality on credit growth. However, Perugini et al. $(2015$, p. 7) implicitly consider a possible interaction between income inequality and credit growth when they state that their "simulations show that increased inequality leads endogenously to credit expansion". Other authors, such as Piketty (1997), suggest that higher steady state interest rates lead to greater wealth inequality.

Morset (2013) modifies a Ramsey-Cass-Koopmans model to incorporate wealth accumulation and asset price behavior. So, they show the negative impact of inequality on real steady state interest rates. This also considers the presence of asset bubbles. Some authors consider the relationship between income inequality and credit. On the one hand, Perugini et al. (2015) observe a positive correlation between distribution of income and private sector indebtedness. On the other hand, Bordo \& Meissner (2012) do not find any relationship.

The article is divided as follows. Section 2 develops a theoretical model that analyzes the fact, without the intervention of the public sector. This is an exogenous model to better show the effects of exogenous shocks. Section 3.1 develops another case in a different model in which the public sector intervenes to avoid economic inequality, also smoothing the trend of GDP. In addition, Section 3.2 sets out the need for a coordination of public policies among the governments of different countries to minimize the effects of black swans and other negative externalities. Finally, Section 4 discusses the results and concludes.

${ }^{3}$ See Lugilde, Bande \& Riveiro (2019) for a literature review. 


\section{Theoretical model with exogenous variables and without public intervention}

A new theoretical model is developed to explain the impact of black swans on income and wealth inequality and the size of the financial sector (Morset, 2013), showing the interaction of the above variables as determinants of economic crises after a random endowment shock caused by a black swan as an effect of the COVID-19 on financial markets. This black swan has a differential impact according to the sector, generating effects on financial wealth and income inequality.

The main assumptions of the model are provided. First, nobody is seeing their income reduced due to the crisis (no increasing of unemployment or unemployment benefits compensate the possible reduction in income, increasing the public deficit). Second, it is also assumed that there is no lockdown (so there are no initial supply restrictions) because the government is seeking alternatives. Finally, only the sectors that are benefited at least once from the crisis are included, considering an asymmetric impact of the crisis between sectors.

So, this is an additional differentiation between sectors compared with others made for the COVID19, for instance, Blanchard \& Illing (2021) distinguish between contact-intensive sectors and the rest, the former being negatively affected. Nonetheless, this paper only considers no contact-intensive sectors, but subdividing by the distinction between pharmaceuticals (industry) and financial sector (financial services can be online), thus considering the main binomial health-economics by these two sectors and how they interact. So, the initial impact of the coronavirus is more beneficial for the pharmaceutical sector than for the financial sector, establishing impact differences between no contact-intensive sectors that can even increase their demand (Blanchard \& Illing, 2021). A further assumption is considering that the drugs or medicines are consumed by all households in the same amount.

Here, an economic crisis is considered to follow the next definition 1:

- Definition 1. There is an economic crisis if, and only if, both GDP and bank profits decline relative to the value of the same variable in the previous period.

Two hypotheses are set forth and will be tested in this paper:

- Hypothesis 1 (H1), An increase in wealth inequality in period $t=1$ is related to an increase in the size of the financial sector in the same period.

- Hypothesis $2(\mathrm{H} 2)$, The joint presence of inequality in period $t=2$ and the size of the financial sector in $t=1$ is related to a decrease in GDP in period $t=2$.

The two hypotheses $(\mathrm{H} 1, \mathrm{H} 2)$ will be tested in this theoretical model. Initially, we assume a close economy without a public sector and with perfect competition. Four agents are considered in a three period model: two households/consumers $(A, B)$, firms and banks, where bank owners are type $A$ consumers, while type $B$ households own pharmaceutical companies. Analyzing the GDP crises, it is not necessary to find the equilibrium conditions of the model, then the identities of the budget restriction of the agents will be shown.

Households provide capital to companies because they are the owners of them, maintaining financial assets in the form of shares listed on the stock market. These stocks provide some capital gains to the consumers if their price goes up $(P)$ and the companies also provide some capital income in the form of dividends. There are two sectors in the economy, a pharmaceutical sector (denoted by $f$ ) that provides real products to consumers, that is, real consumption, and a banking sector (b), which provides financial services to consumers, that is, financial consumption. Wealth, capital, initial loans and deposits are given at the beginning of the initial period. At the end of period $t=0$, household $A$ faces the following budget constraint:

$$
B C_{0}^{A}=w l^{A}+R * S^{A}+\left(\dot{p}_{0}^{A}+d\right)\left(1+\gamma_{0}^{A}+u_{0}\right) p K-C_{0}^{R A}
$$


where $B C_{t}^{i}$ is the budget constraint of household $i$ in period $t$ (if the period indicator does not appear in any variable, it means that the variable remains constant over time), $w$ is the wage, $l$ are the working hours, $R$ the deposit rate that the household receives from the savings at the beginning of the initial period, $S^{i}$ is the initial saving of household $i$. Income from financial assets is the pure interest $A_{t}^{i}=\left(\dot{p}_{t}^{i}+d\right)\left(1+\gamma_{t}^{i}+u_{t}\right) p K$, where $d$ is the dividend and the instantaneous growth of rate of the stock prices is $\dot{p}_{t}^{i}, K$ is the capital amount and $p$ the pure interest rate, in this case the price of the share.

The black swan is defined by $u_{t}$ as a random shock in the value of shares and by $\gamma_{t}^{A}$ as its differential impact between sectors. In this case, the black swan is the COVID-19 pandemic and will have a negative effect in general $\left(u_{1}<0\right)$, but with a differentiate positive impact in the pharmaceutical industry due to the studies on a new vaccine against the coronavirus and the sale of medicine, $\gamma_{1}^{B}+u_{1}>0$.

The banking sector is initially less affected, with a greater impact on the pharmaceutical industry than on banks $\left|\gamma_{1}^{A}\right|<\left|\gamma_{1}^{B}\right|$, because of the poor perspectives of the economy as a whole in the medium term that affect the financial sector because of the uncertainty (Álvarez Espiño, Fernández-López, Rey-Ares \& Castro-González, 2020) and potential instability. On the other hand, a higher use of the financial sector, is expected, at least by the pharmaceuticals.

In period $t$, the variable $C_{t}^{R i}$ is the consumption of real products by individual $i$. While these negative and positive shocks disappear immediately in the short term, and are offset in the long term $E\left(\gamma_{t}^{A}, \gamma_{t}^{B}, u_{t}\right)=0$, where $E$ is the expectation, these shocks allow the economy to grow, and it will be seen that the GDP in the last period with shock will be higher than initially, after a crisis.

So, these black swans are offset by positive endowment shocks that generate economic growth but sometimes generate inequality. That is why the public sector will intervene in the following sections. Returning to the model, consumers have the same type of preferences, they decide the amounts of consumption, financial services and labor. Household $B$ faces the following budget constraint:

$$
B C_{0}^{B}=w l^{B}+\left(\dot{p}_{0}^{B}+d\right)\left(1+\gamma_{0}^{B}+u_{0}\right) p K-r * D^{B}-C_{0}^{R B}
$$

where $D^{B}$ is the loan provided by the banks to $B$ households, who have to pay some loan interests at rate $r$. In this first period $t=0$, wealth inequality is equal to zero, because the assets of $A$ households are equal to those of households $B$ :

$$
t=0: A_{0}^{A}=A_{0}^{B} \Rightarrow \phi_{0}=\left(A_{0}^{A}-A_{0}^{B}\right)^{2}=0
$$

Wealth inequality is defined with $\phi_{t}$ as the square of the difference between assets of the two households in the current period. At $t=0$ there is no wealth inequality, as seen in (3). Below the profits of the non-financial (pharmaceutical) companies appear, which meet the following equation:

$$
\Pi_{0}^{f}=C_{0}^{R A}+C_{0}^{R B}-A_{0}^{B}-w l^{A}=\Pi_{\infty}^{f}=E\left(\Pi_{t}^{f}\right)=C^{R A}+C^{R B}-A^{B}-w l^{A}=0
$$

The profits are zero due to perfect competition. The financial sector provides financial services to their owners ( $A$ consumers), and to the rest of consumers $(B)$. According to Peña (2019), the capital gains from the financial sector are only the pure interests, without considering other interests. Banks obtain the following profits, which are equal to zero in the first period and in the long term due to perfect competition:

$$
\Pi_{0}^{b}=r * D^{B}-A_{0}^{A}-R * S^{A}-w l^{B}=\Pi_{\infty}^{b}=E\left(\Pi_{t}^{b}\right)=r * D^{B}-A^{A}-R * S^{A}-w l^{B}=0
$$

In period $t=1$ there is an exogenous shock as explained above, a black swan in the financial markets like the coronavirus pandemic that becomes an endowment shock. Therefore, there is a negative random shock $\left(u_{1}<0\right)$ that benefits pharmaceutical companies, $\gamma_{1}^{B}+u_{1}>0$, because there 
is an expectation of a vaccine, with a differential impact between sectors $\left|\gamma_{1}^{B}\right|>\left|\gamma_{1}^{A}\right|$ as explained above.

Due to the different impact of the shock on the sectors, now the assets of $B$ households are greater than assets from consumers $A$, generating wealth and income inequality. The causes of this inequality could be a temporary random shock caused, for example, by war or a pandemic.

$$
t=1: A_{1}^{A}<A_{1}^{B} \Rightarrow \phi_{1}=\left(A_{1}^{A}-A_{1}^{B}\right)^{2}>0
$$

A positive inequality of wealth is observed, and to correctly explain the development of the model in the period $t=1$, the behavior of the banks is the first element to look at. $A$ households have a lower asset endowment than $B$ consumers. Because of the pandemic, $A$ and $B$ consumers have to buy drugs from the pharmacies, increasing their total consumption by the same amount as $B^{\prime}$ s assets, $\Delta C_{1}^{R A}+\Delta C_{1}^{R B}=\Delta A_{1}^{B}$, considering that both consume the same amount of drugs. Thus, the company maintains the same profits that at period $0, \Pi_{0}^{f}=\Pi_{1}^{f}=0$. Due to the positive inequality, $A$ households have to request a loan from the bank to maintain the same purchasing power as in the previous period and to buy drugs because the increase in consumption is higher than the increase in assets $\left(\Delta C_{1}^{R A}>\Delta A_{1}^{A}\right)$, ceteris paribus and mutatis mutandis. On the other hand, with a higher net income and wealth endowment than before, $B$ households deposit the difference between the gains from current asset gains and the gains from the previous period in the bank. Then, the bank obtains the following profits:

$$
\Pi_{1}^{b}=r * D^{B}+S^{B}-A_{1}^{A}-D^{A}-R * S^{A}-w l^{B}=0
$$

Type $A$ consumers face to the following budget constraint:

$$
B C_{1}^{A}=w l^{A}+R * S^{A}+A_{1}^{A}+D^{A}-C^{R A}=B C_{0}^{A}
$$

observe that $D^{A}=\Delta C_{1}^{R A}-\Delta A_{1}^{A}$.

Type $B$ households deposit all the increase in asset earnings minus the increase in consumption of real goods (medicines) in the bank, achieving the following budget constraint:

$$
B C_{1}^{B}=w l^{B}-r * D^{B}+A_{1}^{B}-S^{B}-C^{R B}=B C_{0}^{B}
$$

It can be seen that $S^{B}=\Delta A_{1}^{B}-\Delta C_{1}^{R B}>D^{A}=\Delta C_{1}^{R A}-\Delta A_{1}^{A} ; \Delta A_{1}^{B}>\Delta A_{1}^{A}$.

In the second period, $t=2$, the inequality increases, in this case there is still no black swan effect, but the price of shares in the banking sector rises due to the better perspectives of the economy by avoiding the random shock and the increased financial activity, which may be due to a bubble. Hence, there is a reallocation of income among consumers. Type $B$ households, owners of the pharmaceuticals, still hold a higher endowment of financial assets than in period $t=0$ due to the increase of the shares in the stock market, but lower to the previous period $t=1$, due to the the black swan dissappearing. Type $A$ households, owners of the banks, achieve a higher asset allocation than $B$ consumers, higher than the pre-shock allocation, and the increase is also higher than the increase in assets in the pharmaceutical sector in the previous period, when $t=1$. The reason is that, on the one hand, the temporary shock has ended, and there could be equality if other circumstances did not affect the situation. On the other hand, there is a bubble in the financial sector and there are greater dividends and capital due to the increase in share prices of these companies, $\dot{p}_{2}^{A}>\dot{p}_{0}^{A}$. Therefore, type $A$ consumers earn higher capital gains than consumers $B$. As seen, the cause of this inequality of wealth is the increase of the size of the financial sector in the previous period (hypothesis 2).

$$
t=2: A_{2}^{A}>A_{2}^{B} \Rightarrow \phi_{2}=\left(A_{2}^{A}-A_{2}^{B}\right)^{2}>0
$$


Income and wealth inequality in this period is the highest one:

$$
\phi_{0}=0<\phi_{1}<\phi_{2}
$$

In period $t=2$, type $A$ households return the loan with the corresponding interests, and $B$ households withdraw the deposit, receiving interests on the corresponding deposit. Then, the profits for the banking sector are:

$$
\Pi_{2}^{b}=r * D^{B}+(1+r) D^{A}-A_{2}^{A}+I-(1+R) S^{B}-R * S^{A}-w l^{B}=0
$$

Therefore, the increase in the banks' profits is $\Delta \Pi_{2}^{b}=(2+r) * D^{A}-(2+R) * S^{B}-\Delta A_{2}^{A}=0$. In addition, the consumption of real goods is reduced in this period to the situation before the random shock. Therefore, the situation of the companies does not change in terms of profits. Accordingly, type $A$ households face the following budget constraint:

$$
B C_{2}^{A}=w l^{A}+R * S^{A}+A_{2}^{A}-(1+r) D^{A}-C^{R A}=B C_{0}^{A}
$$

while $B$ households meet this other budget constraint:

$$
B C_{2}^{B}=w l^{B}-r * D^{B}+A_{2}^{B}+(1+R) S^{B}-C^{R B}=B C_{0}^{B}
$$

from (12-14) it can easily be deduced that $-\Delta A_{2}^{A}=\Delta A_{2}^{B} / 2$.

Finally, in the period $t=3$ the economy returns to the steady state of $t=0$ and of the long term, thanks to the self-regulation of the economy by the banking sector. According to the above equations, the expressions of the GDP of each period are formulated and compared. Two alternative versions are used to calculate the GDP. First, the income approach is developed and then the consumption approach. Both results are equivalent, which will be useful for the following equations.

The GDP of each period measured by the income approach is:

$$
G D P_{t}^{\text {Income }}=A_{t}^{A}+A_{t}^{B}+w l^{A}+w l^{B}
$$

While the GDP measured by the form of consumption is:

$$
\begin{gathered}
G D P_{0}^{\text {Consumption }}=G D P_{3}^{\text {Consumption }}=C^{R}+C^{F S}=C^{R A}+C^{R B}+r D^{B}-R * S^{A} \\
G D P_{1}^{\text {Consumption }}=C_{1}^{R}+C_{1}^{F S}=C_{1}^{R A}+C_{1}^{R B}+r D^{B}+S^{B}-R * S^{A}-D^{A} \\
G D P_{2}^{\text {Consumption }}=C^{R}+C_{2}^{F S}=C^{R A}+C^{R B}+r D^{B}+(1+r) D^{A}-R * S^{A}-(1+R) S^{B}
\end{gathered}
$$

where $R$ reflects real products and $F S$ is financial services.

Taking into account these equations, it can be checked that there is an increase in GDP from $t=0$ to $t=1^{4}$, a decrease on the amount of GDP from $t=1$ to $t=2$ and an increase in banking activity, and therefore an increase in the banking sector, from $t=0$ to $t=1$ (hypothesis 1 ).

Proposition 1, used to check whether a crisis has begun, is also fulfilled: the banks go into losses and there is a decrease in GDP. Additionally, there is an increase of GDP from $t=0$ to $t=2$ thanks to payment of loan interests.

\footnotetext{
4 In the first period there is an increase on the GDP because no lockdown is considered, and initially the black swan reactivates the economy by the increase of the production of drugs and vaccines and the use of the financial sector. The main reason is that the model only considers no contact-intensive sectors, which demand can even increase (Blanchard \& Illing, 2021).
} 
In period $t=3$, there is no inequality again, because all financial services caused by the initial wealth inequality are compensated. Therefore, all sectors have the same budgetary constraints as in period $t=0$. Although the size of the financial sector increases in periods $t=1$ and $t=2$, however, it is easy to see that in the next period of the crisis, when it is over (in period $t=3$ ), the development of the financial sector would be reduced in respect to the previous period $t=2$, ceteris paribus. The reason is that in the previous period the financial services generated due to inequality of wealth would already be cancelled (withdrawal of deposits and repayment of loans) from the previous period, which would lead to a decrease in the depth of the financial sector. There would also be a decrease in GDP in $t=3$ before coming into the steady-state situation ( $t=3$ is the same case as in $t=0)$.

The main results of the model are:

$$
\begin{gathered}
\triangle G D P_{1}, \Delta F S S_{1}, \Delta F S S_{2}>0 \\
\Delta G D P_{2}<0 \\
G D P_{2}-G D P_{0}>0
\end{gathered}
$$

Evidence is given in the Appendix. The term FSS means "financial sector size". This is a simple example, and it is easy to see that the initial increase in GDP in period $t=1$ produced by the increase in inequality would only be at the beginning, while the decrease in GDP would continue as long as borrowers had to pay the interest on their loan, and finally would decrease more sharply when borrowers had to pay back the loan (in both cases, period $t=2$ ). Therefore, the most common period in the real world is $t=2$, the most frequent and typical period that we will focus on and that could be analyzed empirically as further research.

\section{Endogenous model including the public sector}

This model includes the public sector in order to reduce the inequality of income and wealth or even reduce the negative externalities derived from the black swans by taking into account joint actions with other countries, with the possible decision to coordinate public policies among countries (Calvo Bernardino \& Martín de Vidales Carrasco, 2017). This section provides, first, a way to reduce the income and wealth inequality caused by black swans as the current pandemic does, and second, a governmental alternative to the great lockdown that is less damaging for the economy, i.e., taking global reallocation measures that help reduce the negative externalities of the black swans (in the case of the coronavirus pandemic, for example, providing medical care and support to all countries).

\subsection{The public sector reducing economic inequality}

The public sector tries to minimize the inequality side effect of the coronavirus by establishing a wealth tax through the application of a tax rate on the sectorial shifts on pure interest by the pandemic that affect capital gains (the displacement of financial wealth) and on capital income (corporate dividends), which are affected by the black swan effect of stock market prices. This means that the government can anticipate the effects of the coronavirus, by choosing the tax rate and who will be responsible for paying the tax.

$$
\underset{\left\{\tau^{A}, \tau^{B}\right\}}{\operatorname{Min}} \phi=\left(A_{t}^{A}-A_{t}^{B}\right)^{2}=\left(\left(\left(1-\tau^{A}\right) \gamma_{t}^{A}-\left(1-\tau^{B}\right) \gamma_{t}^{B}\right) p K\right)^{2}
$$

In this case, in the period $t=1$ the economy is not just self-regulating, but the public sector intervenes to avoid the inequality of wealth, minimizing inequality according to each tax rate with the following reaction equations (first order conditions): 


$$
\begin{gathered}
\frac{\partial \phi}{\partial \tau^{A}}=2\left(\left(1-\tau^{A}\right) \gamma_{t}^{A}-\left(1-\tau^{B}\right) \gamma_{t}^{B}\right) p K\left(-\gamma_{t}^{A} p K\right)=0 \\
\frac{\partial \phi}{\partial \tau^{B}}=2\left(\left(1-\tau^{A}\right) \gamma_{t}^{A}-\left(1-\tau^{B}\right) \gamma_{t}^{B}\right) p K\left(\gamma_{t}^{B} p K\right)=0
\end{gathered}
$$

which, by equalizing both equations and operating, leads to:

$$
-\left(1-\tau^{A}\right)\left(\gamma_{t}^{A}\right)^{2}+\left(1-\tau^{B}\right) \gamma_{t}^{A} \gamma_{t}^{B}=\left(1-\tau^{A}\right) \gamma_{t}^{A} \gamma_{t}^{B}-\left(1-\tau^{B}\right)\left(\gamma_{t}^{B}\right)^{2}
$$

Rearranging the terms and clearing for $\tau^{A}, \tau^{B}$ :

$$
\left(\gamma_{t}^{B}\right)^{2}-\left(\gamma_{t}^{A}\right)^{2}=\tau^{B}\left(\gamma_{t}^{A} \gamma_{t}^{B}+\left(\gamma_{t}^{B}\right)^{2}\right)-\tau^{A}\left(\gamma_{t}^{A} \gamma_{t}^{B}+\left(\gamma_{t}^{A}\right)^{2}\right)
$$

It is worth mentioning that the tax rates $\left\{\tau^{A}, \tau^{B}\right\}$ have to be equal to a value between zero and one, but not zero (that means no tax), neither one (this would be a confiscatory tax). Then, according to the above equation:

$$
\text { If } \gamma^{A}<\gamma^{B} \Rightarrow \tau^{A}<\tau^{B} \quad \text { If } \gamma^{A}>\gamma^{B} \Rightarrow \tau^{A}>\tau^{B}
$$

Since the objective of the public sector is to avoid economic inequality, in the first case $\tau^{A}$ would choose zero and in the second case $\tau^{B}$ would also choose zero. If $\gamma^{A}=\gamma^{B} \Rightarrow \tau^{A}=\tau^{B}=0$, in which a tax makes no sense because there would be no inequality to eliminate. In the first and second case, the specification of $\tau^{B}$ and $\tau^{A}$ would be, respectively:

$$
\tau^{B}=\frac{\left(\gamma_{t}^{B}\right)^{2}-\left(\gamma_{t}^{A}\right)^{2}}{\gamma_{t}^{A} \gamma_{t}^{B}+\left(\gamma_{t}^{B}\right)^{2}}, \tau^{A}=\frac{\left(\gamma_{t}^{A}\right)^{2}-\left(\gamma_{t}^{B}\right)^{2}}{\gamma_{t}^{A} \gamma_{t}^{B}+\left(\gamma_{t}^{A}\right)^{2}}
$$

It should be noted that public intervention in this case is only by reallocation of income, which means that the economy is not affected because tax collection is done in the form of direct public transfers based on equality, giving households type $A$ and $B$ exactly half of the total tax collection.

\subsection{Theorem on the need for a coordination of policies between the different countries affected}

This epigraph presents a theorem that claims the need for a coordination of policies to compensate for negative global externalities like systemic black swans such as the novel coronavirus pandemic. In this case, instead of a direct transfer, the public sector provides public expenditure in the form of positive externalities such as infrastructure, research, innovation and development, public services, public goods, etc., which would mitigate the perverse effects of such a black swan that could take the form of a pandemic, war or hunger -promoting its abolition- (Serageldin, 2011).

In this case, policies for mitigating the economic effects of the COVID-19 crisis could be reducing income inequality or even promoting the public provision of vaccines or drugs. Thus, a model is developed that is different from the previous sections, in which there are $j=1 \ldots m$ countries and $i=1 \ldots n$ inhabitants for each country, a personal income of $y$, and a total world income of $Y$. The tax rate is applied to the shifts of capital wealth provoked by the COVID-19.

Public expenditure is equal to tax revenue, with global public expenditure, being $\bar{G}=\tau \gamma_{t} p K$, where $\gamma_{t}$ is the average differential effect of the black swan among sectors, $G=\tau \gamma_{t} p K / m$ is the national public expenditure and $g=(1-i) \tau \gamma_{t} p K / n m$ is the public spending assigned to each individual. The optimization problem of a joint public policy is:

$$
\underset{t}{\operatorname{Max}} W_{G S}=\sum_{j}^{m} \sum_{i}^{n} b_{i j}(g)+\sum_{j}^{m} b_{j}(G)+b(\bar{G})-\sum_{j}^{m} d_{j}(G)-d(\bar{G})
$$


where the public sector maximizes social welfare by using the tax rate as an instrument, $b$ is the positive externality of the public spending and $d$ the administrative costs of establishing a supranational policy for all governments. The individual positive externalities of having a national government are $b_{i j}(g)$, while the global benefits of a joint policy "fighting" to the income inequality provoked by black swans are $b(\bar{G})$.

After replacing the public expenditure by its specification, it leads to:

$$
\operatorname{Max}_{t} W_{G S}=\sum_{j}^{m} \sum_{i}^{n} b_{i j}\left(\frac{\tau \gamma_{t} p K}{n m}\right)+\sum_{j}^{m} b_{j}\left(\frac{\tau \gamma_{t} p K}{m}\right)+b\left(\tau \gamma_{t} p K\right)-\sum_{j}^{m} d_{j}\left(\frac{\tau \gamma_{t} p K}{m}\right)-d\left(\tau \gamma_{t} p K\right)
$$

The costs of administration would be $d_{j}(G)$ for a national government and $d(\bar{G})$ for a global state. By replacing the costs and benefit functions with their Cobb-Douglass expression, we have:

$$
\operatorname{Max}_{t} W_{G S}=n m B\left(\frac{\tau \gamma_{t} p K}{n m}\right)^{\beta}+m B\left(\frac{\tau \gamma_{t} p K}{m}\right)^{\beta}+\left((1-i) \tau \gamma_{t} p K\right)^{\beta}-m D\left(\frac{\tau \gamma_{t} p K}{m}\right)^{\alpha}-\left(\tau \gamma_{t} p K\right)^{\alpha}
$$

So, by solving the problem of optimization, the following condition is provided

$$
\begin{aligned}
\frac{\partial W_{G S}}{\partial t} & =n^{1-\beta} m^{1-\beta} B(1-i)^{\beta} \tau^{\beta-1} \gamma_{t}^{\beta} p^{\beta} K^{\beta}+m^{1-\beta} B \tau^{\beta-1} \gamma_{t}^{\beta} p^{\beta} K^{\beta}+B \tau^{\beta-1} \gamma_{t}^{\beta} p^{\beta} K^{\beta}- \\
& -m^{1-\alpha} D \tau^{\alpha-1} \gamma_{t}^{\alpha} p^{\alpha} K^{\alpha}-D \tau^{\alpha-1} \gamma_{t}^{\alpha} p^{\alpha} K^{\alpha}=0
\end{aligned}
$$

whose second derivative is negative, so the next optimal tax rate is a maximum:

$$
\tau_{G S}^{*}=\left[\left(\frac{1+m^{1-\alpha}}{1+m^{1-\beta}+n^{1-\beta} m^{1-\beta}}\right)\left(\frac{\alpha}{\beta}\right)\right]^{\frac{1}{\beta-\alpha}}
$$

This result is obtained considering that, for the sake of simplicity, $B c^{\beta} Y^{\beta}=D c^{\alpha} Y^{\alpha}$. In this economy, we consider an alternative case without a coordinated policy, so there is a kind of world anarchy (Vinci, 2008), in which the global welfare is obtained as the sum of the national welfare of the $m$ countries, with each $j$ country maximizing the following national welfare:

$$
\operatorname{Max}_{t} W_{j}=n m B\left(\frac{\gamma_{t} p K}{n m}\right)^{\beta}+m B\left(\frac{\gamma_{t} p K}{m}\right)^{\beta}-m D\left(\frac{\gamma_{t} p K}{m}\right)^{\alpha}
$$

Under the same assumptions, the optimal tax rate for these countries would be

$$
\tau_{j}^{*}=\left[\left(\frac{m^{1-\alpha}}{m^{1-\beta}+n^{1-\beta} m^{1-\beta}}\right)\left(\frac{\alpha}{\beta}\right)\right]^{\frac{1}{\beta-\alpha}}
$$

In this case, it is easy to see that the optimal tax rate in $G S$ (global solution by coordinated policies) is higher than in the "anarchical" organization of countries if, and only if, $1+n^{1-\beta}>m^{\beta-\alpha}$. Therefore, the establishment of a global state would be beneficial for the economy if, and only if:

$$
W_{G S^{-}} \sum_{j}^{m} W_{j}=\tau_{G S}^{\beta}+m^{1-\beta}\left(\tau_{G S}^{\beta}-\tau_{j}^{\beta}\right)+n^{1-\beta} m^{1-\beta}\left(\tau_{G S}^{\beta}-\tau_{j}^{\beta}\right)-\tau_{G S}^{\alpha}-m^{1-\alpha}\left(\tau_{G S}^{\alpha}-\tau_{j}^{\alpha}\right)>0
$$

This leads us to three main cases. The first occurs when the preferences for public services and the returns to scale of the implementation and maintenance costs of the administrations are the same $(\beta=\alpha)$ or both functions tend to have constant returns to scale $(\beta \rightarrow 1 \wedge \alpha \rightarrow 1)$. Then, welfare will be higher in the situation with the higher tax rate, so a coordination of public policies will be more 
beneficial than anarchy only if the tax rate in the former case is higher. The reason is that the optimal tax rate would be the highest in both cases.

The second always leads to greater benefits for the joint policies. This case is when the benefit function of preferences has constant or increasing returns to scale, but not the cost function of production. In this case, the optimal tax rate will be higher in the case of a policy coordination and welfare will always be higher in the latter.

The third main case is when the cost function presents constant or increasing returns to scale, but not the benefit function. In this case, the optimal tax rate with a world public policy will always be higher than without it, but the preferences between coordination or anarchy would be ambiguous. It would depend on the variables. For instance, if $\beta \rightarrow 0$, then anarchy would be preferable.

\section{Discussion of results and conclusions}

The results show how a shock on the initial wealth endowment can alter wealth inequality and this fact may expand financial deepening, increasing GDP $(t=1)$. Furthermore, it may lead to even greater wealth inequality than in the next period $(t=2)$, while encouraging a decrease in the GDP and bank profits. The theoretical explanation would be that an asymmetric shock on asset endowment affects wealth inequality per se, leading to an increase in the size of the financial sector and an increase in total income. The reason is that consumers have to maintain the same purchase power. This leads to a higher level of inequality when consumers have to repay their loans and withdraw their deposits, which reduces GDP. After that, the economy returns to the starting point. In the mid-term, precautionary saving has risen.

The raise of GDP (eq. 19) is empirically corroborated by studying the correlation of the discovery of the COVID-19 vaccine and the advanced indicator of GDP, the price of the shares on the stock, shifting from 68,802 to 73,527 points in a day, as Figure 1 shows. In fact, there is a highly significant positive correlation $\left(R^{2}=91.88 \%\right.$ with constant, $59.3 \%$ without $)$ between the stock prices and a dummy that takes the value 1 if the vaccine was already discovered, for the daily period from the $1^{\text {st }}$ of September, 2020 , to the $20^{\text {th }}$ of January, 2021.

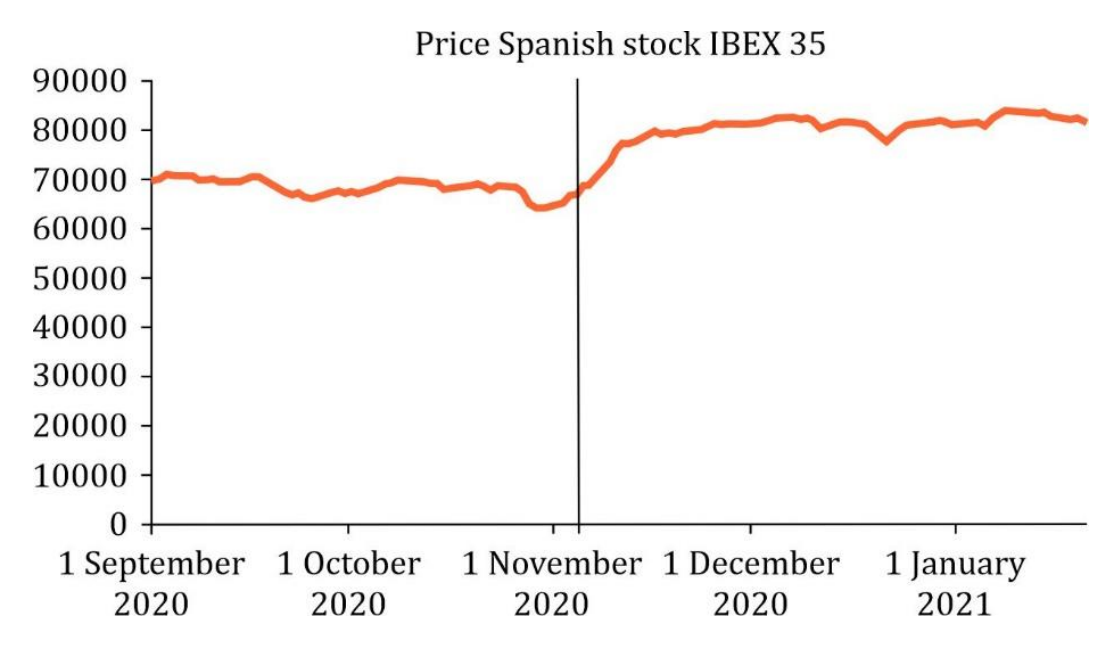

Figure 1. Stock regarding when the announcement of a vaccine, $9^{\text {th }}$ of November. Source: own elaboration based on Bolsa de Madrid.

The second models, which are endogenous, reflect the possible alternatives the public sector has face the economic crisis derived from the health and public policies implemented after COVID-19. 
These policies may be solutions even for other kinds of black swans. The first proposal consists of, first, taxing those who have benefited from the crisis, and second, distributing tax revenues proportionally among taxpayers. The other solution could be to unify public policies of all countries, or at least some, to avoid the negative externalities that are a consequence of the black swans. In this case, the main drivers are consumer preferences for public services and the costs of creating a new and coordinated policy, but also the tax rate to fund it.

Regarding public policies across the world in order to mitigate the effects of the COVID-19, public policies from Israel are remarkable. Concretely, the policy of rapidly implementing the vaccines already since December of 2020. Currently, this country enjoys herd immunity. Furthermore, this can also positively affect the income inequality, reducing it. As we have no recent data of income inequality, unemployment rates from the Organisation for Economic Cooperation and Development (OECD) database are used as a proxy, considering that, according to Jantti (1994), Mocan (1999) and Cysne (2009), unemployment may be significative and positively correlated with income inequality. It is found that, with the greatest available monthly data of unemployment rates for that country, from January 2012 to November 2020 unemployment was 5\%, and after starting the vaccination, from December 2020 to March 2021 it was the same average. If we compare it with another small country with a similar unemployment rate during the pre-vaccine period, Iceland, we can see that unemployment has risen while in Israel it remained stable, mainly due to the vaccination program of the state. The European country reached a $4.7 \%$ on average from $2012 \mathrm{M} 01$ to $2020 \mathrm{M} 11$, similar to Israel. Nonetheless, during the same period from 2020M12 to 2021M03 when the proxy of income inequality remained stable for Israel, in Iceland the unemployment rate peaked to $7.2 \%$ on average.

The main conclusions are the following. Firstly, it can be observed that a temporary shock may cause short-term fluctuations, but these alterations can be compensated in the long term by the financial sector, causing an economic crisis along the path and an increase in wealth inequality. A black swan can initially be seen as a business opportunity that may increase economic growth in the shortterm if the right policies are put in place. Secondly, the self-mechanisms of the financial sector can exacerbate potential wealth inequality, so the public sector might intervene. Third, the private sector could lean to the same previous balance without the public sector, generating wealth inequality. In fact, a policy measure would be public sector intervention in this economy to reduce the risk of economic crises by redistributing wealth in a way that helps to make the size of the financial sector more reasonable. Finally, it is proposed that a public policy coordination among countries is needed to prevent black swans and other negative externalities, in which a joint policy will be preferable when the preferences for public services are equal to the returns of scale of the costs of the management of public administrations and the tax rate in this situation is higher than without coordination. Alternatively, coordinated policies are preferred when the function of preferences shows constant or increasing returns to scale but these returns are not shown in the function of costs.

\section{Appendix}

1. There is an increase in the GDP of the economy from 0 to 1 period, measured by the income method.

$$
\Delta G D P_{1}=G D P_{1}^{\text {Income }}-G D P_{0}^{\text {Income }}=A_{1}^{A}+A_{1}^{B}+w l^{A}+w l^{B}-A_{0}^{A}-A_{0}^{B}-w l^{A}-w l^{B}=\Delta A_{1}^{A}+\Delta A_{1}^{B}>0
$$

2. There is a decline in GDP from period 1 to 2, measured by the income method.

$$
\Delta G D P_{2}=G D P_{2}^{\text {Income }}-G D P_{1}^{\text {Income }}=A_{2}^{A}+A_{2}^{B}+w l^{A}+w l^{B}-A_{1}^{A}-A_{1}^{B}-w l^{A}-w l^{B}=\Delta A_{2}^{A}+\Delta A_{2}^{B}<0
$$

3. There is an increase in the size of the financial sector from period 0 to period 1.

$$
\Delta F S S_{1}=F S S_{1}-F S S_{0}=r D^{B}+S^{B}+R * S^{A}+D^{A}-R * S^{A}-r D^{B}=D^{A}+S^{B}>0
$$


4. There is an increase of the GDP in the economy from 0 to 1 period, measured by the consumption method, knowing that $\Delta C_{1}^{R B}=\Delta C_{1}^{R A}$.

$$
\begin{aligned}
\Delta G D P_{1} & =G D P_{1}^{\text {Consumption }}-G D P_{0}^{\text {Consumption }}= \\
& =C_{1}^{R A}+C_{1}^{R B}+r D^{B}+S^{B}-R * S^{A}-D^{A}-C_{0}^{R A}-C_{0}^{R B}-r D^{B}+R * S^{A}= \\
& =C_{1}^{R A}+C_{1}^{R B}-C_{0}^{R A}-C_{0}^{R B}+S^{B}-D^{A}=\Delta A_{1}^{B}+\Delta A_{1}^{A}>0
\end{aligned}
$$

5. There is an increase in the size of the financial sector from 1 to 2 period.

$$
\begin{aligned}
\Delta F S S_{2} & =F S S_{2}-F S S_{1}=(1+r) D^{A}+(1+R) S^{B}+R * S^{A}+r D^{B}-D^{A}-S^{B}-R * S^{A}-r D^{B}= \\
& =r D^{A}+R S^{B}>0
\end{aligned}
$$

6. There is a decrease of the GDP of the economy from period 1 to 2, measured by the consumption method.

$$
\begin{aligned}
\Delta G D P_{2} & =G D P_{2}^{\text {Consumption }}-G D P_{1}^{\text {Consumption }}= \\
& =C^{R A}+C^{R B}+r D^{B}+(1+r) D^{A}-R * S^{A}-(1+R) S^{B}-C_{1}^{R A}-C_{1}^{R B}-r D^{B}+D^{A}+R * S^{A}-S^{B}= \\
& =-\Delta C_{1}^{R A}-\Delta C_{1}^{R B}+(2+r) D^{A}-(2+R) S^{B}<0
\end{aligned}
$$

Because $-\Delta A_{2}^{A}=\Delta A_{2}^{B} / 2$ as derived above.

7. There is a decline in the GDP of the economy from period 0 to 2 , measured by the consumption method.

$$
\begin{aligned}
G D P_{2}^{\text {Consumption }} & -G D P_{0}^{\text {Consumption }}=G D P_{2}^{\text {Consumption }}-G D P_{0}^{\text {Consumption }}= \\
& =C^{R A}+C^{R B}+r D^{B}+(1+r) D^{A}-R * S^{A}-(1+R) S^{B}-\left(C^{R A}+C^{R B}+r D^{B}-R * S^{A}\right)= \\
& =(1+r) D^{A}-(1+R) S^{B}>0
\end{aligned}
$$

\section{References}

Adams-Prassl, A., Boneva, T., Golin, M., \& Rauh, C. (2020). Inequality in the impact of the coronavirus shock: Evidence from real time surveys, Journal of Public economics, 189, 104245. DOI: https://doi.org/10.1016/i.jpubeco.2020.104245

Álvarez Espiño, M., Fernández-López, S., Rey-Ares, L., \& Castro-González, S. (2020). Capacitación y comportamiento financiero de la generación millennial en España. Revista Galega de Economía, 29(3), 1-19. DOI: https://doi.org/10.15304/rge.29.3.7045

Amankwah-Amoah, J., Khan, Z., \& Wood, G. (2020). COVID-19 and business failures: The paradoxes of experience, scale, and scope for theory and practice. European Management Journal, 39 (2), 179-184. DOI: https://doi.org/10.1016/i.emj.2020.09.002

Benito, A. (2006). Does job insecurity affect household consumption? Oxford Economic Papers, 58(1), 157-181. DOI: https://doi.org/10.1093/oep/gpi041

Blanchard, O., \& Illing, G. (2021). The COVID-19 pandemic (version January 2021). München, Germany: Pearson Studium.

Bordo, M. D., \& Meissner, C. M. (2012). Does inequality lead to a financial crisis? Journal of International Money and Finance, 31(8), 2147-2161. DOI: https://doi.org/10.1016/j.jimonfin.2012.05.006

Brunnermeier, M. K., \& Koby, Y. (2018). The reversal interest rate. NBER Working Paper No. 25406. Cambridge, MA: National Bureau of Economic Research (NBER).

Retrieved from: https://www.nber.org/system/files/working papers/w25406/w25406.pdf

Calvo Bernardino, A., \& Martín de Vidales Carrasco, I. (2017). Crisis financiera y reestructuración de las cajas de ahorro en España, 2003-2013. Revista Galega de Economía, 26(1), 5-18. DOI: https://doi.org/10.15304/rge.26.1.4306

Carroll, C. D., \& Samwick, A. A. (1998). How important is precautionary saving? Review of Economics and Statistics, 80(3), 410-419. DOI: https://doi.org/10.1162/003465398557645

Chamon, M., Liu, K., \& Prasad, E. (2013). Income uncertainty and household savings in China. Journal of Development Economics, 105, 164-177. DOI: https://doi.org/10.1016/i.jdeveco.2013.07.014 
Cysne, R. P. (2009). On the positive correlation between income inequality and unemployment. The Review of Economics and Statistics, 91(1), 218-226.

Davola, A. (2020). From the black swan, to the snowball. Risks of COVID-19 pandemic for consumer credit scores in the lack of a harmonized regulatory intervention. Opinio Juris in Comparatione [Forthcoming]. DOI: http://dx.doi.org/10.2139/ssrn.3604031

Furceri, D., Loungani, P., Ostry, J. D., \& Pizzuto, P. (2020). Will Covid-19 affect inequality? Evidence from past pandemics. Covid Economics. Vetted and Real-Time Papers, 12, 138-157.

Galletta, S., \& Giommoni, T. (2020). The effect of the 1918 influenza pandemic on income inequality: Evidence from Italy (June 24, 2020). Social Science Research Network (SSRN). DOI: http://dx.doi.org/10.2139/ssrn.3634793

Gros, D. (2020). The great lockdown: Was it worth it? CEPS Policy Insights, No. 2020-11. Brussels, Belgium: Centre for European Policy Studies (CEPS). Retrieved from: https://www.ceps.eu/wp-content/uploads/2020/05/PI2020-11_DG_The-great-lockdown.pdf

Jantti, M. (1994). A more efficient estimate of the effects of macroeconomic activity on the distribution of income. Review of Economics and Statistics, 76(2), 372-378. DOI: https://doi.org/10.2307/2109895

Küçükçayli, F. M., \& Akinci, G. Y. (2020). Is COVID-19 the new black swan of the financial markets? On the linkage between COVID-19 and stock markets. Modern Economy, 201.

Lugilde, A., Bande, R., \& Riveiro, D. (2019). Precautionary saving: A review of the empirical literature. Journal of Economic Surveys, 33(2), 481-515. DOI: http://dx.doi.org/10.1111/joes.12284

Menegatti, M. (2010). Uncertainty and consumption: New evidence in OECD countries. Bulletin of Economic Research, 62(3), 227-242. D0I: http://dx.doi.org/10.1111/j.1467-8586.2009.00316.x

Mocan, N. H. (1999). Structural unemployment, cyclical unemployment and income inequality. The Review of Economics and Statistics, 81(1), 122-134. DOI: https://www.jstor.org/stable/2646791

Morset, T. L. (2013). Inequality as a cause of systemic banking crises-some new theory and evidence. (Master Thesis). Lund University. Retrieved from: https://lup.lub.lu.se/student-papers/search/publication/3814887

Peña, G. (2019). Efficient treatment of banking services under VAT. Economics and Business Letters, 8(2), 115-121. DOI: https:// doi.org/10.17811/ebl.8.2.2019.115-121

Perugini, C., Hölscher, J., \& Collie, S. (2015). Inequality, credit and financial crises. Cambridge Journal of Economics, 40(1), 227-257. DOI: https://doi.org/10.1093/cje/beu075

Piketty, T. (1997). The dynamics of the wealth distribution and the interest rate with credit rationing. The Review of Economic Studies, 64(2), 173-189. DOI: https://doi.org/10.2307/2971708

Sayed, A., \& Peng, B. (2020). Pandemics and income inequality: A historical review. Covid Economics. Vetted and Real-Time Papers, 52, 96-117.

Schumpeter, J. A. (1912). The theory of economic development. Cambridge, MA: Harvard University Press.

Serageldin, I. (2011). Abolishing Hunger. TATuP-Zeitschrift für Technikfolgenabschätzung in Theorie und Praxis, 20(2), 14-20. DOI: https://doi.org/10.14512/tatup.20.2.14

Taleb, N. N. (2007). The black swan: The impact of the highly improbable, vol. 2. Random House.

Vinci, A. (2008). Anarchy, failed states, and armed groups: Reconsidering conventional analysis. International Studies Quarterly, 52(2), 295-314. Retrieved from: https://www.jstor.org/stable/29734236 